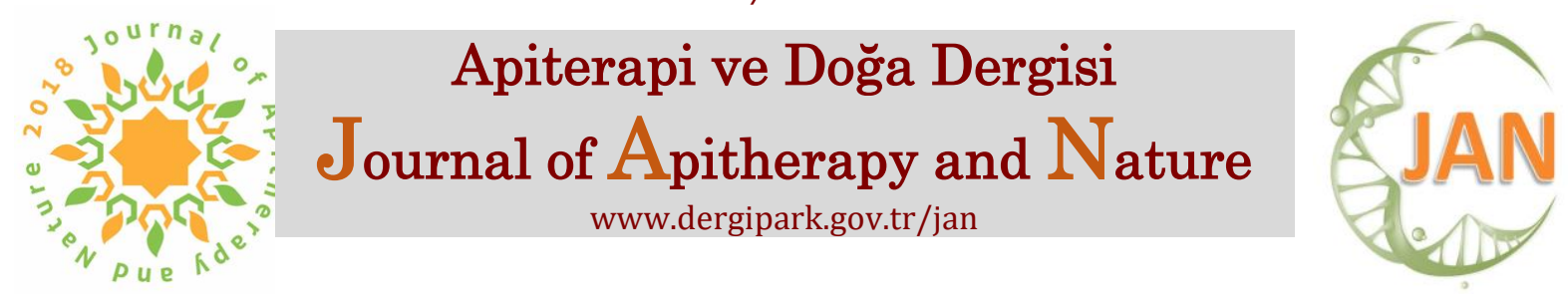

\title{
The Importance of Propolis in Combating COVID-19
}

\section{COVID-19 ile Mücadelede Propolisin Önemi}

\author{
Meltem UÇAR ${ }^{1 *}$ \\ ${ }^{1}$ Medical Laboratory Technique, Vocational School of Health Services, European University of Lefke, Lefke, \\ Northern Cyprus, TR-10 Mersin, Turkey \\ *mucar@eul.edu.tr, ORCID: 0000-0001-5554-2622
}

Received/Geliş Tarihi: 03/05/2021

Accepted/ Kabul Tarihi: 24/06/2021

doi: $10.35206 /$ jan. 932050

*Corresponding author / Yazışılan yazar

e-ISSN: 2667-4734

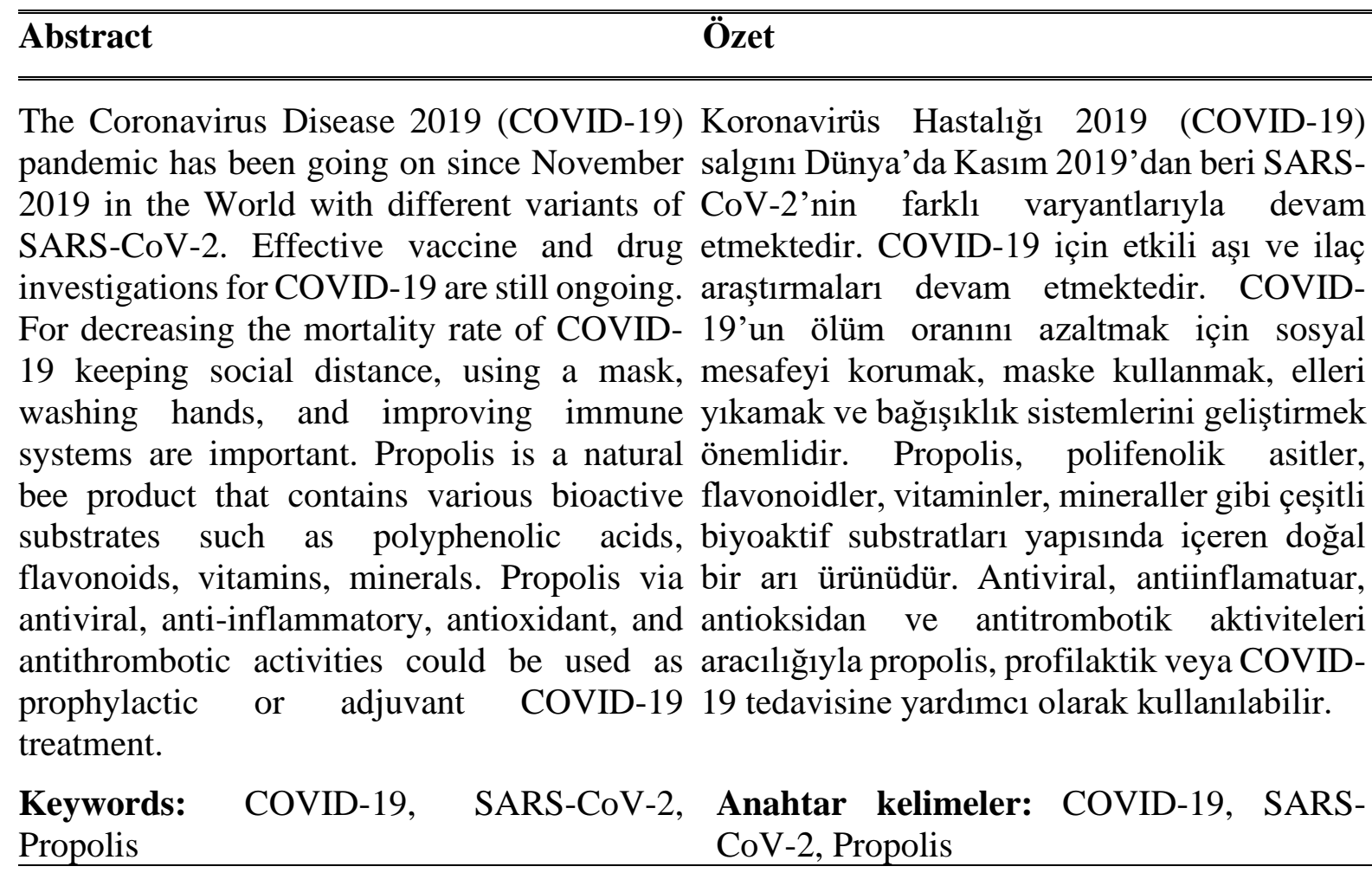

Abbreviations: COVID-19, Coronavirus disease 2019, WHO, World Health Organization, SARS-CoV, Severe Acute Respiratory Syndrome Coronavirus-2, CoV, Coronaviruses, ACE-2, Angiotensin-Converting Enzyme 2, TMPRSS2, Transmembrane Serine Protease 2, PAK 1, RAC/CDC42-activated kinase 1, IL, Interleukin, TNF$\alpha$, Tumor necrosis factor-alpha, IFN $\gamma$, Interferon-gamma, G-CSF, Granulocyte colony-stimulating factor RdRp, RNA-dependent RNA polymerase, PL-pro, Papain like protease, M-pro, Coronavirus main proteinase, CAPE, Caffeic acid phenethyl ester, HIV, Human Immunodeficiency Virus, NF- $\kappa$ B, Nuclear factor kappa-light-chainenhancer, 3CL-pro, 3C-like proteinase, COX, Cyclooxygenase, iNOS, inducible nitric oxide synthase, NO, Nitric oxide, PAI-1, Plasminogen activator inhibitor-1, BGP, Brazillian Green Propolis, EPP-AF®, The Standardized Propolis Extract 


\section{INTRODUCTION}

As of April 26 $6^{\text {th }}$, 2021, the world is still laboring to overcome coronavirus disease 2019 (COVID-19) in 223 countries, over 146841882 cases, and 3104743 deaths have been reported by World Health Organization (WHO) (WHO, 2021a). COVID-19 is caused by Severe Acute Respiratory Syndrome Coronavirus-2 (SARS-CoV-2) which was firstly identified in Wuhan, China, in December 2019. COVID-19 may have various symptoms, such as fever, headache, exhaustion, sputum, hypogeusia, painful throat, dyspnea, cough, diarrhea, anorexia, dizziness, rhinorrhea, nasal congestion, hyposmia, myalgia (Kim et al., 2020; Singhal, 2020; Vipul et al., 2020). Most infected people will develop mild to moderate illness and recover without hospitalization. While most common symptoms are fever, dry cough, and tiredness, serious symptoms are difficulty breathing or shortness of breath, chest pain or pressure, loss of speech or movement. Otherwise, some patients haven't any symptoms too during the illness. When someone is contaminated or infected with the SARS-CoV-2 it can take 5-6 days or take up to 14 days for getting symptoms (WHO, 2021b). Polymerase Chain Reaction (PCR), Real TimePolymerase Chain Reaction (RT-PCR), Complete Blood Count and other laboratory tests, Xray, and CT scans are used to diagnose COVID-19. CT imaging is more sensitive and specific for diagnosing COVID-19. WHO is suggested using all symptoms, RT-PCR and other laboratory tests, and CT imaging for diagnosing infection and emphasis that only PCR test is not enough for diagnosis COVID-19 (Feng et al., 2020; Singhal, 2020; Zitek, 2020). Infection is transmitted human to human among asymptomatic and symptomatic patients by coughing, sneezing, or touching contaminated surfaces (Singhal, 2020). People who are 65 or >65 years old or who have a chronic disease such as diabetes mellitus, chronic liver disease, chronic lung disease, chronic renal failure, chronic cardiovascular disease, hematological malignancy, and receiving chemotherapy or immunosuppressive agents are in the high-risk groups for COVID19 (Kim et al., 2020). Rapid detection, treatment, and prevention of COVID-19 are very important for saving lives in the world urgently. Social distancing, lockdown of cities, hygienic products have been used to control the COVID-19 Pandemic (Lima et al., 2020). Scientists are still developing more effective vaccines and drugs for COVID-19 (Al Naggar et al., 2021). Medical plants, some compounds that are isolated from plants, and bee products such as propolis, honey which have antiviral activity are used by people for preventing COVID-19 and supporting immune systems and treatment (Berretta et al., 2020; Ripari et al., 2021). This review summarizes the information on COVID-19 disease, the anti-viral activity of propolis, and its effects on SARS-CoV-2. 


\section{SARS-COV-2}

Coronaviruses $(\mathrm{CoV})$ are a group of positive-sense single-stranded RNA viruses. SARS-CoV2 uses spike glycoproteins for attaching Angiotensin-Converting Enzyme 2 (ACE 2) and Transmembrane Serine Protease 2 (TMPRSS2) of the host cell than resulting membrane fusing (Dalan et al., 2021; Elmahallawy et al., 2021; Harisna et al., 2021). Figure 1 shows the structure of SARS-CoV-2 (Elmahallawy et al., 2021). SARS-CoV-2 includes 4 structural proteins (Spike, Envelope, Membrane, and Nucleocapsid proteins), Cysteine proteinase, RNA polymerase, and nonstructural proteins (Elmahallawy et al., 2021; Sahlan et al., 2021).

ACE-2 is a receptor not only for Angiotensin II but also SARS-CoV-2 too. ACE-2 is expressed in the ciliated airway epithelium of the lungs, enterocytes of the small intestine, arterial and venous endothelial cells, arterial smooth muscle cells in the heart, kidneys, adrenal glands, pancreas, skeletal muscle, and adipose tissues (Dalan et al., 2020). Because of the wide expression of ACE-2, using inhibitors of TMPRSS2 is more useful for preventing enter of SARS-CoV-2 into the host cell (Hoffmann et al., 2020).

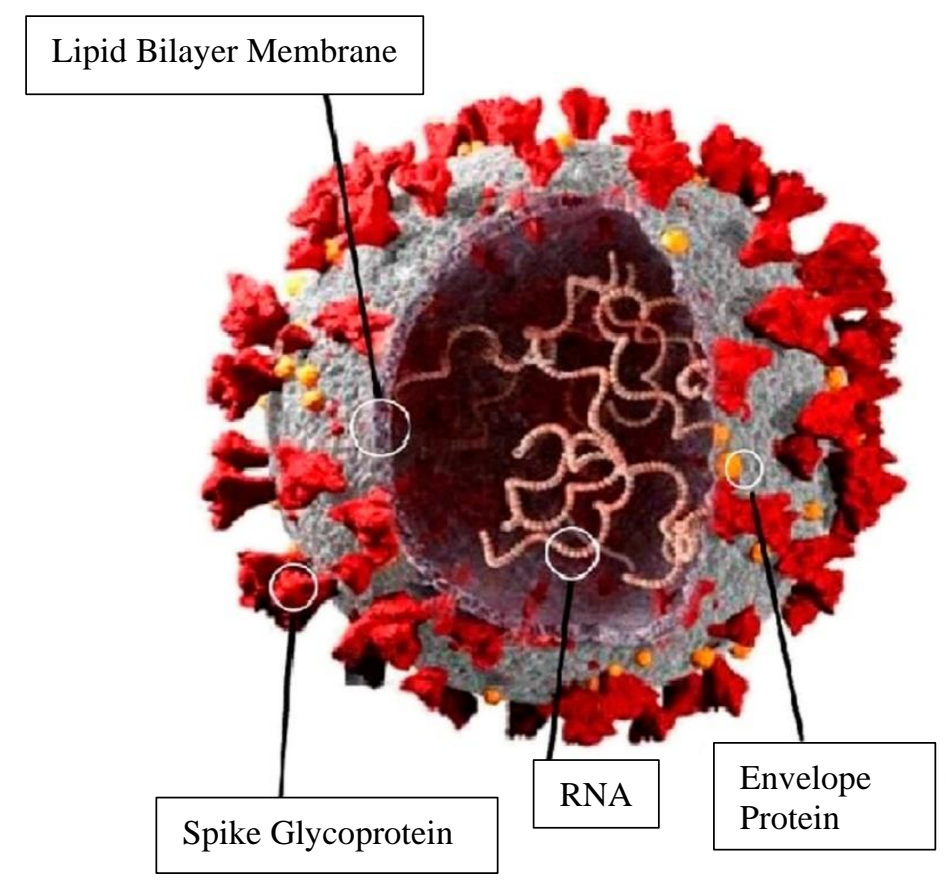

Figure 1. Structure of SARS-CoV-2.

Due to the imbalance of ACE-2 pathways patients with hypertension, type II diabetes, or cardiovascular disease belong to high-risk groups for respiratory failure and morality in COVID-19. As there is not enough evidence that shows the harmful or beneficial effects of using ACE-inhibitors or Angiotensin 2 Tip 1 receptor blockers for preventing COVID-19 in 
high-risk group patients, all patients should continue to take their medicine as before (Dalan et al., 2020). Figure 2 shows host cell and SARS-CoV-2 (Coronavirus (SARS-CoV-2) Viral Proteins, Sigma-Aldrich, 2021). Besides ACE-2 and TMPRSS2, RAC/CDC42-activated kinase 1 (PAK 1) is also a target for the scientist to prevent COVID-19. After SARS-CoV-2 enters the host cell PAK 1 upregulation has occurred which causes lung inflammation, lung fibrosis, and other mortality factors (Dalan et al. 2020). Activation of PAK 1 that also known as pathogenic kinase is related to various diseases/disorders such as cancers, malaria, inflammation, and viral infection including Human Immunodeficiency Virus (HIV), influenza, and COVID-19 (Maruta $\& \mathrm{He}, 2020)$. Increased PAK 1 in a host cell induces replication of SARS-CoV-2 and inhibits immune response too (Dalan et al., 2020). The other problem in COVID-19 patients is cytokine storm that occurred after increased production of proinflammatory cytokines such as Interleukins (IL) (IL2, IL-6, IL7, IL-10), Tumor necrosis factor-alpha (TNF $\alpha$ ), Interferongamma (IFN $\gamma$ ), Granulocyte colony-stimulating factor (G-CSF). Cytokine storms may cause multi-organ system failure that is a life-threatening disorder (Elmahallawy et al., 2021). The other mechanism for fighting against SARS-CoV-2 is suppressing its replication by different agents. RNA-dependent RNA polymerase ( $\mathrm{RdRp})$ that catalyzes the synthesis of coronavirus RNA, is so important for coronaviral replication/transcription machinery complex. Also, Papain like protease (PL-pro) and coronavirus main proteinase (M-pro) that has a role to replicate and generate new RNA are therapeutic targets for developing pharmacy too (Huang et al., 2020).

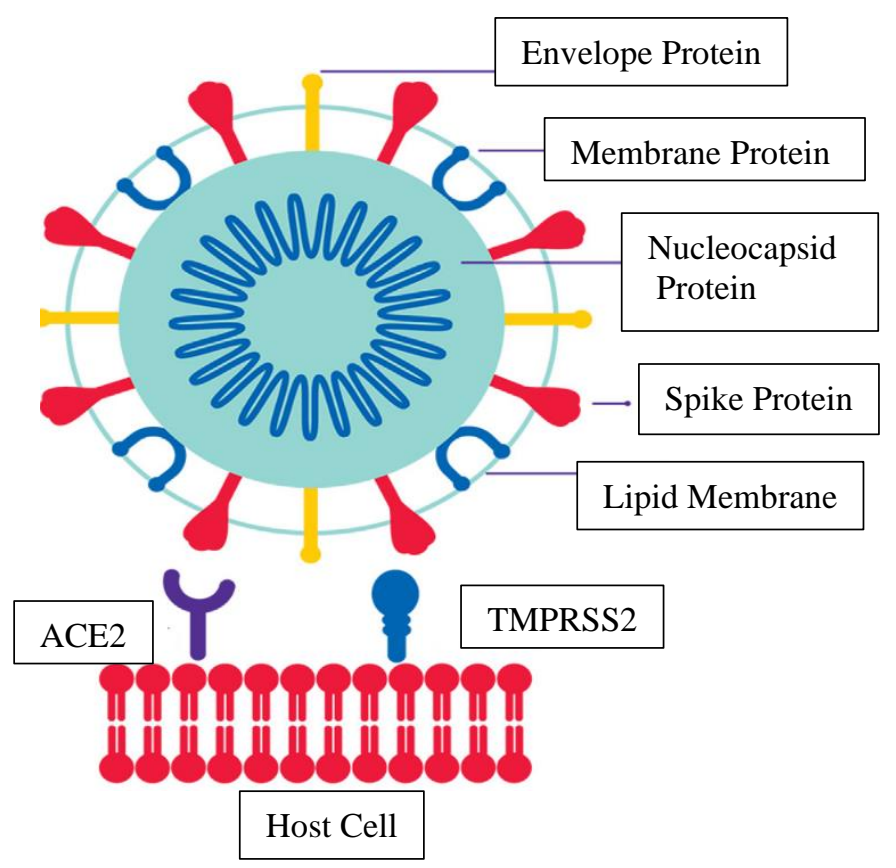

Figure 2. Host cell and SARS-CoV-2 
Several drugs were investigated to treatment COVID-19 such as nevilnafir, as a RdRp inhibitor remdesivir, ribavirin, favipiravir, as a protease and proteinase inhibitor lopinavir and darunavir, as a PAK 1 blocker melatonin, ciclesonide, ivermection, ketorolac, chloroquine, and hydrochloroquine and propolis (Harisna et al., 2021; Huang et al., 2020; Maruta \& He, 2020). Also, several reports suggest that chloroquine and hydrochloquine caused serious arrhythmia, kidney injuries, liver problems, blood and lymph system disorders, and failure in patients with COVID-19 (United States Food and Drug Administration, 2020).

Some SARS-CoV-2 mutations repressive vaccine developments, affect the affinity to ACE-2 receptor and infectiousness. and immune response (Conti et al., 2021; Huang et al., 2020; Volz et al., 2021; Zhang et al., 2020). Different mutants form of SARS-CoV-2 found in the United Kingdom, Brazil, and Sound Africa and recently double mutant SARS-CoV-2 found in India. Scientists need time to be sure this variant is more deadly or more transmissible (https://www.bbc.com/news/world-asia-india-56507988). On the other hand, various supplements, herbal and apitherapy products such as ginseng extracts, garlic extracts, echinacea, curcumin extracts, propolis, honey, royal jelly, bee wax, bee venom, bee pollen, quercetin, Vitamin C, Vitamin D, Vitamin E, zinc, selenium used to support treatment of COVID-19 by antiviral, anti-inflammatory, antioxidant and immunomodulatory activities (Ali \& Kunugi, 2021; Al Naggar et al., 2021; Jin et al., 2020; Keflie et al., 2021).

\section{PROPOLIS}

Propolis is a bee product that occurred by molding resinous balsam of plants and trees with bee wax and saliva. Propolis is also known as bee glue originates from Greek and occurred Pro- (in meaning for or defense) and -polis (in meaning city) word parts that are a defense of city or hive. Bees use propolis as a detoxification agent and fixing material for their hives to maintain homeostasis, to promote a beneficial microbiome, and protect from insects and animals (Burdock, 1998; Zulhendri et al., 2021). Propolis is also used by Egyptians, Greeks, Romans, and Incas for wound healing, corpse embalming, and antipyretic. It was used in Europe in the $17^{\text {th }}$ and $20^{\text {th }}$ centuries as an antibacterial agent and during the Second World War due to the antimicrobial and anti-inflammatory activity (Santos et al., 2019). Propolis compositions and colors can change depending on the geographic area, climate. Generally, propolis colors are dark brown, dark green, and dark yellow. Some propolis samples were shown in Figure 3 (Çolak, 2009). 
Propolis consists of 50\% resins, $30 \%$ bee wax, $10 \%$ aromatic and essential oils, $5 \%$ bee pollen, 5\% multiple organic compounds, vitamins, and minerals (Ali \& Kunugi, 2021). It includes more than 300 different compounds such as flavonoids, phenolic acids, phenolic acid esters, terpenoids, xanthones, fatty acids, volatile fatty acids, ketones, lactones, steroids, pollens, various minerals, vitamins. Some phenolic compounds and flavonoids found in propolis are shown in Table 1 (Çolak, 2009; Duca et al., 2019; Santos et al., 2019;).

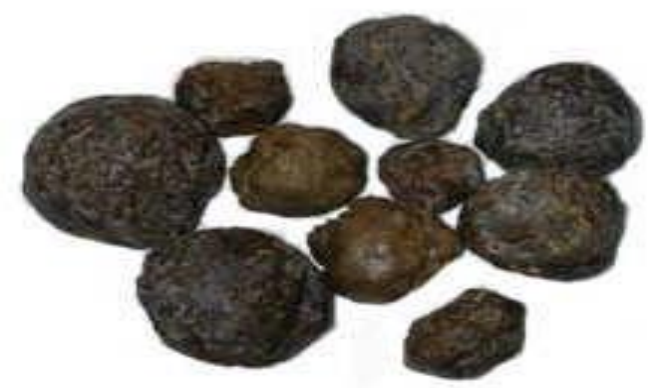

Figure 3. Propolis samples

Propolis can solve with ethanol, methanol, diethyl ether, acetone, toluene, trichloroethylene, oils, water, and others with different ratios and compositions (Burdock, 1998; Ripari et al., 2021). Commercial many kinds of extracts with different concentrations may find in markets and pharmacies in capsule, liquid, pastilles or supplement form alone or with the other herbals, vitamins or minerals. As for its antibacterial and antimicrobial activities, it is used for the production of toothpaste and mouthwash solutions. (Burdock, 1998; Santoset al., 2019; Zulhendri et al., 2021). Propolis is also used by the food industry and cosmetic industry especially its antibacterial, antioxidant, and antiaging properties, and recently it is famous and important in veterinary medicine too (Santos et al. 2019). 
Table 1. Some flavonoids and phenolic compounds found in propolis

\begin{tabular}{cc}
\hline Flavonoids & Phenolic Compounds \\
\hline Apigenin & 1,1-dimethylallylcaffeate \\
\hline Chrysin & 2,2-dimethyl-6-carboxyethenyl-2H-1-benzopyran \\
\hline Formononetin & 3-(4-hydroxy-3-(oxo-butenyl)-phenylacrylic acid \\
\hline Hesperetin & 3,5-diphenyl-4-hydroxycinnamic acid derivate \\
\hline Kaempferol & p-Coumaric acid \\
\hline Medicarpin & Caftepillin C \\
\hline Naringenin & Caffeic acid phenethyl ester (CAPE) \\
\hline Neovestiol & Resveratrol \\
\hline Pinocembrin & Feruric acid \\
\hline Quercetin & Isoliquiritigenin \\
\hline Vestitol & Mono/Dicaffeoylquinic acids \\
\hline Galangin &
\end{tabular}

Propolis has various biological activities for humans such as antioxidant, antiinflammatory, antibacterial, antifungal, antiviral, antimutagenic, antitumoral, anticancer, cytotoxic, anti-proliferative, anti-angiogenic, immunomodulatory (Brakhuis, 2019; Burdock, 1998; Zulhendri et al., 2021). Figure 4 summarise the use of propolis with its properties for bees and humans (Zulhendri et al., 2021).

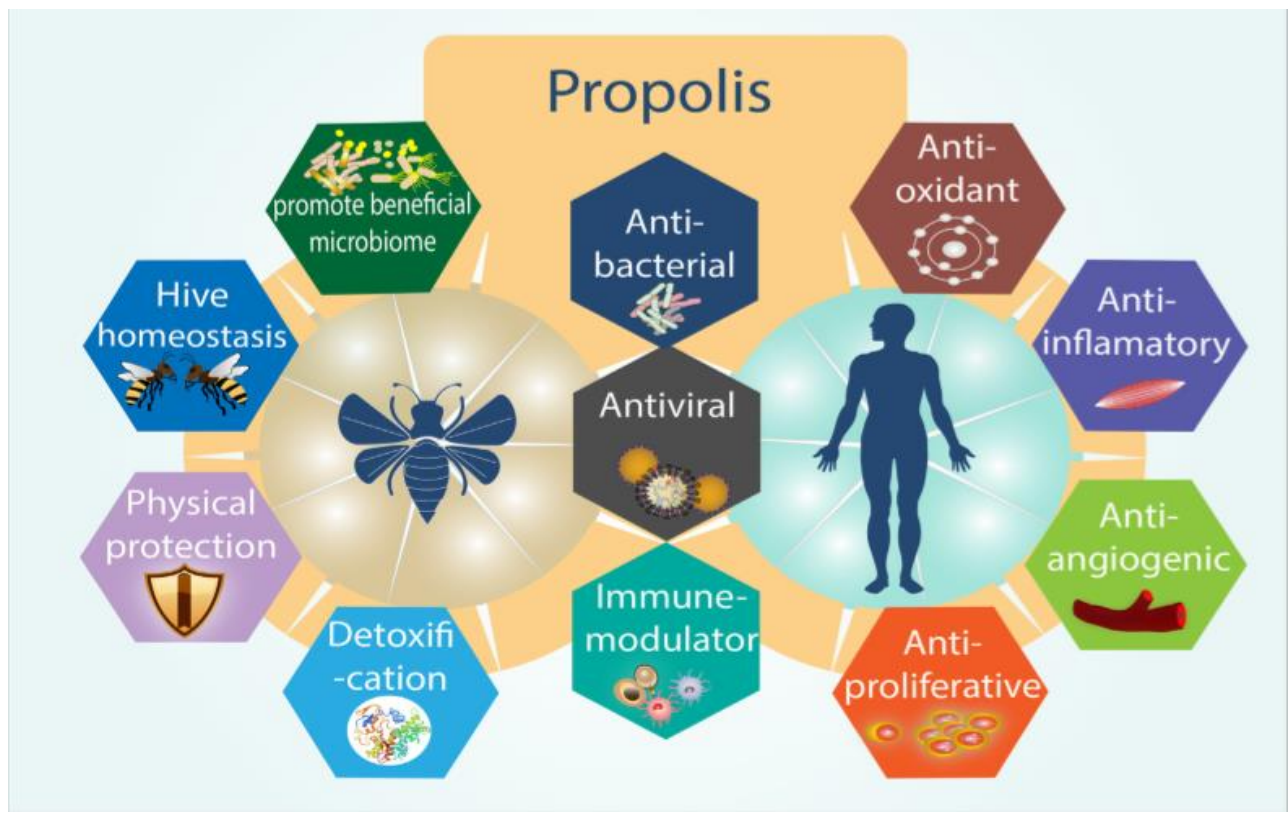

Figure 4. The use of propolis by bees and humans 


\section{USE OF PROPOLIS IN WAR WITH CORONAVIRUS}

As mentioned before propolis and propolis-derived compounds such as CAPE, benzoic acid, resveratrol, p-cumaric acid, quercetin, chrysin, pinocembrin, and galangin have antiviral, antiinflammatory, antioxidant, and antithrombotic activity. In previous studies, it was shown that propolis and its extracts have antiviral activity against both DNA and RNA virus such as Herpes Simplex Virus Type 1 and Type 2, Adenovirus Type 2, Vesicular Stomatitis Virus, Poliovirus Type 2, Varicella zoster virus, HIV, Influenza. (Burdock, 1998; Governa et al., 2019; Haris et al., 1997; Labska et al., 2018; Yildirim et al., 2016). It was reported that various propolis fractions affected the replication of Vaccinia Virus, Newcastle Disease Virus, and Influenza Viruses A and B (Burdock, 1998). Debiagi et al. (1990) reported that kaempferol and chrysine were reduced the replication of several Herpes Viruses, Adenoviruses, and a Rotavirus concentration-dependently and quercetin was reduced infectivity and intracellular replications of viruses in high concentrations. Also, Erdemli et al. (2015) suggested that CAPE inhibits the HIV-1 infection, nuclear factor kappa-light-chain-enhancer (NF- $\mathrm{kB})$ production, and Hepatitis C virus replication too. Singh et al. (2020) showed that hesperidin has a higher binding activity to RdRp of SARS-CoV-2 than remdesivir, and many polyphenols such as myricetin, epigallocatechin gallate, theaflavin, theaflavin-3'-O-gallate, theaflavin-3'-gallate, theaflavin 3,3'-digallate, quercetagetin, and myricetin strongly bind to the active site of RdRp and other polyphenols such as quercetin, curcumin, kaempferol, epicatechin can bind to RdRp with lower binding energy than remdesivir. It was concluded that some natural polyphenols can be used as an inhibitor of RdRp of SARS-CoV-2.

On the other hand, Maruta \& He (2020) suggested that caffeic acids, CAPE, Artepillin C, nymphaeols inhibit PAK1 activity, act like PAK1 inhibitors, and could be useful for inhibiting or preventing COVID-19-induced lung fibrosis and stimulating the immune system. Also, 3C-like proteinase (3CLpro) is an important enzyme that has a role replication of the virus. It was shown that 2',4'-dihydroxychalcone and 2',4'-dihyroxy-3'-methoxychalcone that also found in propolis have potential repressing properties against 3CLpro. As amyrin (Triterpenes), procyanidin and proanthocyanidin influence the activity of 2'-o-ribose methyltransferase, propolis compounds have potential restrictive properties against methyltransferase too (Elmahallawy et al., 2021). Ali \& Kunugi (2021) reviewed that rutin, nicotiflorin, luteolin, CAPE, and Artepillin $\mathrm{C}$ inhibit viral replication and inflammatory reactions by affecting 3CLpro/Mpro, PLpro, RdRp, and B56 regulatory unit of phosphatase 2A. Sahlan et al. (2021) and Kumarb et al. (2020) showed that propolis components glyasperin 
A, broussoflavonol F, and CAPE have binding affinity to SARS-CoV-2 main protease and have therapeutic value for COVID-19.

Also, Khayrani et al. (2021) detected that propolis components glyasperin A, broussoflavonol F, sulabiroins A, isorhamnetin, and (25)-5,7-dihydroxy-4'-methoxy-8prenylflavanone have the potential to inhibit the binding of ACE-2 and SARS-CoV-2. As phenolic compounds of propolis such as galangin, p-coumaric acid, quercetin, chrysin, and kaempferol could block or reduce the adsorption and entrance of the virus into the host cells, propolis consumption might be useful for protecting COVID-19 and supporting adaptive immune response (Lima et al., 2020). In previous in vitro and in vivo studies, it was shown that flavonoids could inhibit the activity of ACE. Recently Guler et al. (2021) used ten flavonoids (Caffeic acid, CAPE, chrysin, galangin, myricetin, rutin, hesperetin, pinocembrin, luteolin, and quercetin) for detecting their binding ability to ACE-2 receptors and it was shown that rutin has the best inhibition potentials for ACE-2 receptors and then followed by myricetin, CAPE, hesperetin, and pinocembrin. It was concluded that flavonoids in ethanolic propolis extracts have a high potential for COVID-19 treatment by inhibition of ACE-2 receptors and preventing entry of virus to host cells (Guler et al., 2021). Also, Refaat et al. (2021) and Vijayakumar et al. (2020) established that rutin, luteolin, and CAPE inhibit ACE 2 receptors too. Kumara et al. (2020), showed that CAPE inhibits the TMPRSS2 and block the entry of SARS-CoV-2 into the cell. Refaat et al. (2020) and Jain et al. (2021) detected that naringin, rutin, and quercetin have the binding activity to $\mathrm{S}$ protein and inhibit viral fusion in the host cell membrane. Harisna et al. (2021) suggested that propolis components genistin, methylophopogonone A and 3'methoxydaidzin inhibit main protease and spike protein and these compounds could be used as antiviral agents.

The other mechanism of antiviral activity of propolis may be related to its zinc content. Propolis has variable amounts of zinc such as $21 \mathrm{mg} / \mathrm{kg}$ or $9326 \mathrm{mg} / \mathrm{kg}$ (Cvek et al., 2008; Tosic et al., 2017). Zinc ions inhibit viral enzymes that are important for the replication of the virus in the host cells (te Velthuis et al., 2010). Kaushik et al. (2017) reported that zinc salts block hepatitis E virus replication by inhibiting of RdRp. Also, zinc has the potential to threaten COVID-19 by antioxidant, anti-inflammatory, and immunomodulatory properties. Zinc can suppress the expressing of various chemokines, acute phase proteins such as fibrinogen and Creactive protein, proinflammatory cytokines, and some factors that have a role in inflammatory responses such as inhibition of $\mathrm{NF \kappa B}$ and modulation of $\mathrm{T}$ cell functions that cause cytokine storms in COVID-19 (Keflie et al., 2021). 
Another trace element in propolis is selenium that has a role in maintaining adaptive immune systems, inhibiting proinflammatory cytokines, chemokines, and production of free oxygen radicals. Experimentally it was shown that a selenium-deficient diet in mice is related to developing lung injury in post-influenza virus infections (Keflie et al., 2021; Suhupharani et al., 2019). Suhupharani et al. (2019) biosynthesized selenium nanoparticles from ethanolic extracts of propolis for human health due to the antimicrobial and antioxidant activity of selenium.

Also, it was established that Vitamin A, Vitamin B12, Vitamin C, Vitamin D, Folate, Pyridoxine, Nicotinamide, and Retinoic acid have a protective role against COVID-19 by antioxidant, antiviral, anti-inflammatory activities and affecting the immune response (Keflie et al., 2021). It is also known that propolis has many kinds of vitamins and micronutritions and it could support immune systems too (Burdock, 1998; Marcucci, 1995).

Additionally, the anti-inflammatory activity of propolis is related to its components such as phenolic acids and their esters, flavonoids, steroids, terpenoids, and amino acids. The basic mechanisms of anti-inflammatory activity of propolis are the inhibition of cyclooxygenase (COX) and prostaglandin biosynthesis, antioxidant activity, inhibition of nitric oxide (NO) synthesis, reducing the level of cytokines, and immunosuppressive activity (Braakhuis, 2019). In many studies it was reported that CAPE, quercetin, naringenin, pinocembrin, Artepillin C, terpenoids showed anti-inflammatory activity by inhibiting COX-2, suppressing the production of prostaglandins and leukotrienes, reducing the expression of inflammatory mediators such as IL-10, IL-1 $\beta$, inducible nitric oxide synthase (iNOS) and inhibiting the production of TNF- $\alpha$,

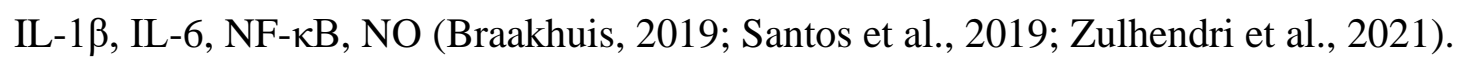

Tromboembolism, thrombosis, and microthrombosis are common in COVID-19 patients and associated with high mortality rates of COVID-19. Generally, anticoagulants use to reduce mortality. In a previous study antithrombotic effect of propolis was also established by decreasing platelet aggregation, other thrombosis-related parameters and suppressing lipopolysaccharide-induced increases in plasminogen activator inhibitor-1 (PAI-1) in mice (Berreta et al., 2020). Quercetin might use for thrombotic disease treatment as a thrombin inhibitor. Quercetin may utilize blood clotting dysregulation conduced by viral infection (Berreta et al., 2020; Shi et al., 2012). In an in vivo study, it was detected that CAPE inhibits collagen-induced platelet aggregation via downregulating Tromboksane B2, COX-1, and 5hydroxytryptamine and increasing NO and cyclic guanosine monophosphate activity. In addition, it was shown that CAPE, galangin, pinostropin inhibit platelet aggregation and 
propolis components including CAPE have the potential to threaten thrombotic disease (Ohkura et al., 2020).

Duarte Silveria et al. (2021) used nan-alcoholic preparation of Brazillian Green Propolis (BGP) The Standardized Propolis Extract (EPP-AF®) at two concentrations (400 mg and 800 $\mathrm{mg}$ ) for 82 hospitalized adult COVID-19 patients and evaluated the patient's length of hospital stay, dependence on oxygen therapy, development of acute kidney injury, intensive care unit admission and use of vasoactive drugs. $400 \mathrm{mg}$ BGP EPP-AF® has 21.2 total flavonoids such as quercetin and $54 \mathrm{mg}$ of total phenolics, such as gallic acid. It was shown that BPG treatment decreased the length of hospital stay (6 days for $400 \mathrm{mg}$ BGP EPP-AF®, 7 days for $800 \mathrm{mg}$ BGP EPP-AF®, and 12 days for the control group $(n=42))$ and renal injury significantly, but didn't have any effect on the need for oxygen therapy and didn't observe any side effect of propolis. In a case report BGP (EPP-AF®) confirmed a COVID-19 patient who was 52 years old in a dose of 45 drops/3 times/day for 2 weeks. Patients viral clearance occurred within 12 days of treatment (Fiorini et al., 2021) Kosari et al. (2021) used a syrup that contains $1.6 \mathrm{mg}$ Hyoscyamus niger L. extract and $450 \mathrm{mg}$ propolis per $10 \mathrm{~mL}$, in 25 COVID-19 patients aged between 17-85 and 25 patients also classified as placebo group in the investigation. In this study, $10 \mathrm{~mL}$ syrup was administered during the 6 days three times a day. It was shown that syrup reduced the clinical symptoms of COVID-19 such as dry cough, shortness of breath, sore throat, chest pain, headache, dizziness, fever, abdominal pain, and diarrhea but didn't have any effect on nausea and vomiting. The dose of propolis at $500 \mathrm{mg} /$ day is approximately equal to 30 drops of propolis extract (11\% w/v of dry matter). Berretta et al. (2020) claim that 30 drops/day or one capsule might be used for preventing purposes of propolis but Soroy et al. (2014) suggested that $1200 \mathrm{mg} /$ day water extract of propolis capsule (Propoelix ${ }^{\mathrm{TM}}$ ) could decrease the level of TNF- $\alpha$ and length of hospitalized day and increase platelet count in 31 patients with dengue hemorrhagic fever that is caused by the mosquito-borne dengue viruses.

\section{CONCLUSIONS}

While production and developing SARS-CoV-2 vaccines and drugs are continued individually people should protect themselves by having potent immunity as well as using masc, antiseptics, keeping social distance, and washing hands against COVID-19. Natural products such as propolis could be useful for improving immune response by immunomodulatory activity, protecting binding, entry, and colonization of SARS-CoV-2 in the host cells of people by antiviral activity, preventing cytokine storms and thrombosis, various tissue injuries such as 
lung, kidney by the antioxidant, anti-inflammatory and antithrombotic activity in COVID-19 patients. Also, it is important to increase the number of randomized and controlled clinical trials to assess the benefits and therapeutic potential of propolis in COVID-19. But people who haven't any allergies to propolis might use propolis for protecting themselves against SARSCoV-2 and COVID-19.

\section{REFERENCES}

Al Naggar, Y., Giesy, J.P., Abdel-Daim, M. M., Ansari, M. J., Al-Kahtani, S. N. \& Yahya, G. (2021) Fighting against the second wave of COVID-19: Can honeybee products help protect against the pandemic? Saudi Journal of Biological Sciences, 28(3), 1519-1527. doi.org/10.1016/j.sjbs.2020.12.031

Ali, A. M. \& Kunugi, H. (2021). Propolis, bee honey, and their components protect against Coronavirus Disease 2019 (COVID-19): A review of in silico, in vitro, and clinical studies. Molecules, 26(5), 1232. doi.org/10.3390/molecules26051232

Berretta, A. A., Silveira, M. A. D., Capcha, J. M. C.\& De Jong, D. (2020). Propolis and its potential against SARS-CoV-2 infection mechanisms and COVID-19 disease Running title: Propolis against SARS-CoV-2 infection and COVID-19. Biomedicine \& Pharmacotherapy, 131, 110622. doi.org/10.1016/j.biopha.2020.110622

Braakhuis, A. (2019). Evidence on the health benefits of supplemental propolis. Nutrients, 11(11), 2705. doi.org/10.3390/nu11112705

Burdock, G.A. (1998). Review of the biological properties and toxicity of bee propolis (propolis). Food and Chemical Toxicology, 36(4), 347-363. doi.org/10.1016/S02786915(97)00145-2

Cvek, J., Medic-Saric, M., Vitali, D., Vedrina-Dragojevic, I., Smit, Z. \& Tomic, S. (2008). The content of essential and toxic elements in Croatian propolis samples and their tinctures. Journal of Apicultural Research and Bee World, 47(1), 35-45. doi.org/10.1080/00218839.2008.11101421

Conti, P., Caraffa, A., Gallenga, C.E., Kritas, S. K., Frydas, I., Younes, A., Emidio, P.D., Tetè, G., Pregliasco, F. \& Ronconi, G. (2021). The British variant of the new coronavirus-19 (SarsCov-2) should not create a vaccine problem. Journal of Biological Regulators and Homeostatic Agents, 35(1), 1-4. doi.org/10.23812/21-3-E 
Coronavirus (SARS-CoV-2) Viral Proteins, Sigma-Aldrich. (2021) Retrieved April 28, 2021 from https://www.sigmaaldrich.com/technical-documents/protocols/biology/ncovcoronavirus-proteins.html. In text reference: (Coronavirus (SARS-CoV-2) Viral Proteins, Sigma-Aldrich, 2021)

Coronavirus: 'Double mutant' Covid variant found in India, 2021. Retrieved April 29, 2021, from https://www.bbc.com/news/world-asia-india-56507988. In text reference: (Coronavirus: 'Double mutant' Covid variant found in India, 2021).

Çolak, M. (2009, Summer). Effects of Bee Pollen and Propolis Extracts on Expression of Voltage-Gated Sodium Channels in Metastatic Human Prostate Cancer Cell Lines. [Ph.D. thesis, Karadeniz Technical University]. Available from Council of Higher Education and Theses database. (Thesis No. 266646)

Dalan, R., Bornstein, S. R., El-Armouche, A., Rodionov, R. N., Markov, A., Wielockx, B., Beuschlein, F. \& Boehm, B. O. (2020). The ACE-2 in COVID-19: Foe or friend? Hormone and Metabolic Research, 52, 257-263. doi.org/10.1055/a-1155-0501

Debiaggi, M., Tateo, F., Pagani, L., Luini, M. \& Romero, E. (1990). Effects of propolis flavonoids on virus infectivity and replication. Microbiologica, 13(3), 207-13.

Duarte Silveira, M. A., De Jong, D., dos Santos Galvao, E. B., Ribeiro, J. C., Silva, T. C., Berratta, A. A., Amorim, T. C., San Martin, R. L. A., da Rebelo Conceiçao, L. F. M., Gomes, M. M. D., Teixeira, M. B., de Souza, S. P., dos Santos, M. H. C., de Oliveira Silva, M., Lírio, M., Moreno, L., Sampaio, J. C. M., Mendonça, R., Ultchak, S. S., ... da Hora Passos, R. (2021). Efficacy of propolis as an adjunct treatment for hospitalized COVID-19 patients: A randomized, controlled clinical trial. Biomedicine and Pharmacotherapy, 138, 111526. doi.org/10.1016/j.biopha.2021.111526

Duca, A., Sturza, A., Moacă, E.-A., Negrea, M., Lalescu, V.-D., Lungeanu, D., Dehelean, C. A., Muntean, D. M. \& Alexa, E. (2019). Identification of Resveratrol as bioactive compound of propolis from Western Romania and characterization of phenolic profile and antioxidant activity of ethanolic extracts. Molecules, 24(18), 3368. doi.org/10.3390/molecules24183368

Erdemli, H. K., Akyol, S., Armutcu, F. \& Akyol, O. (2015). Antiviral properties of caffeic acid phenethyl ester and its potential application. Journal of Intercultural Ethnopharmacology, 4(4), 344-347. doi.org10.5455/jice.20151012013034 
Feng, H., Liu, Y., Lv, M. \& Zhong, J. (2020). A case report of COVID-19 with false negative RT-PCR test: necessity of chest CT. Japanese Journal of Radiology, 38(5), 409-410. doi.org/10.1007/s11604-020-00967-9

Fiorini, A. C., Scorza, C. A., de Almeida, A. -C. G., Fonseca, M. C. M., Finsterer, J., Fonseca, F. L. A. \& Scorza, F. A. (2021). Antiviral activity of Brazilian Green Propolis extract against SARS-CoV-2 (Severe Acute Respiratory Syndrome-Coronavirus2) infection: Case report and review. Clinics, 76, e2357. doi.org/10.6061/clinics/2021/e2357

Governa, P., Cusi, M. G., Borgonetti, V., Sforcin, J. M., Terrosi, C., Baini, G., Miraldi, E. \& Biagi, M. (2019). Beyond the biological effect of a chemically characterized Poplar Propolis: Antibacterial and antiviral activity and comparison with Flurbiprofen in cytokines release by LPS-stimulated human mononuclear cells. Biomedicine, 7(4), 73. doi.org/10.3390/biomedicines7040073

Guler, H. B., Tatar, G., Yildiz, O., Belduz, A. O. \& Kolayl1, S. (2021), Investigation of potential inhibitor properties of ethanolic propolis extracts against ACE-II receptors for COVID-19 treatment by molecular docking study. Archives of Microbiology, doi.org/10.1007/s00203-02102351-1

Haris, Z., Rubinstein, A., Golodner, M., Elmaliah, M. \& Mizrachi, Y. (1997). Suppression of HIV-1 replication by propolis and its immunoregulatory effect. Drugs Under Experimental And Clinical Research, 23(2), 89-96.

Harisna, H. A., Nurdiansyah, R., Syaifie, P. H., Nugroho, D. W., Saputro, K. E., Firdayani, Prakoso, C. D., Rochman, N. T., Maulana, N. N., Noviyanto, A. \& Mardliyati, E. (2021) In silico investigation of potential inhibitors to main protease and spike protein of SARS-CoV-2 in propolis. Biochemistry and Biophysics Reports, 26, 100969. doi.org/10.1016/j.bbrep.2021.100969

Hoffmann, M., Kleine-Weber, H., Schroeder, S., Krüger, N., Herrier, T., Erichsen, S., Schiergens, T. S., Herrler, G., Wu, N.-H., Nitsche, A., Müller, M. A., Drosten, C. \& Pöhlmann, S. (2020). SARS-CoV-2 cell entry depends on ACE2 and TMPRSS2 and is blocked by a clinically proven protease inhibitor. Cell, 181(2), 271-280. doi.org/10.1016/j.cell.2020.02.052 Huang, J., Song, W., Huang, H. \& Sun, Q. (2020). Pharmacological therapeutics targeting RNA-Dependent RNA Polymerase, Proteinase and Spike Protein: From mechanistic studies to 
clinical trials for COVID-19. Journal of Clinical Medicine, 9(4), 1131. doi.org/10.3390/jcm9041131

Jain, A. S., Sushma, P., Dharmashekar, C., Beelagi, M. S., Prasad, S. K., Shivamallu, C., Prasad, A., Syed, A., Marraiki, N. \& Prasad, K. S. (2021). In silico evaluation of flavonoids as effective antiviral agents on the spike glycoprotein of SARS-CoV-2. Saudi Journal of Biological Sciences, 28(1), 1040-1051. doi.org/10.1016/j.sjbs.2020.11.049

Jin, Y.-H., Cai, L., Cheng, Z.-S., Cheng, H., Deng, T., Fan, Y.-P., Fang, C., Huang, D., Huang, L.-Q., Huang, Q., Han, Y., Hu, B., Hu, F., Li, B.-H., Li, Y.-R., Liang, K., Lin, L.-K., Luo, L.S., Ma, J.,...Wang, X. H. (2020). A rapid advice guideline for the diagnosis and treatment of 2019 novel coronavirus (2019-nCoV) infected pneumonia (standard version), Military Medical Research, 7, 4. doi.org/10.1186/s40779-020-0233-6

Kaushik, N., Subramani, C., Anang, S., Muthumohan, R., Shalimar, Nayak, B., Ranjith-Kumar, C.T. \& Surjita, M. (2017). Zinc salts block Hepatitis E Virus replication by inhibiting the activity of Viral RNA-Dependent RNA Polymerase. Journal of Virology, 91(21), e00754-17. doi.org/10.1128/JVI.00754-17

Khayrani, A. C., Irdiani, R., Aditama, R., Pratami, D. K., Lischer, K., Ansari, M. J., Chinnathambi, A., Alharbi, S. A., Almoallim, H. S. \& Sahlan, M. (2021). Evaluating the potency of Sulawesi propolis compounds as ACE-2 inhibitors through molecular docking for COVID-19 drug discovery preliminary study. Journal of King Saud University-Science, 33, 101297. doi.org/10.1016/j.jksus.2020.101297

Keflie, T. S., Phil, M. \& Biesalski, H. K. (2021). Micronutrients and bioactive substances: Their potential roles in combating COVID-19. Nutrition, 84, 111103. doi.org/10.1016/j.nut.2020.111103

Kim, G.-u., Kim, M. -J., Ra, S. H., Lee, J., Bae, S., Jung, J. \& Kim, S. -H. (2020). Clinical characteristics of asymptomatic and symptomatic patients with mild COVID-19. Clinical Microbiology and Infection, 26(7), 948.e1-948.e3. doi.org/10.1016/j.cmi.2020.04.040

Kosari, M., Noureddini, M., Khamechi, S. P., Najafi, A., Ghaderi, A., Sehat, M. \& Banafshe, H. R. (2021). The effect of propolis plus Hyoscyamus niger L. methanolic extract on clinical symptoms in patients with acute respiratory syndrome suspected to COVID-19: A clinical trial. Phytotherapy Research, 2021, 1-7. doi.org/10.1002/ptr.7116 
Kumar $^{a}$, V., Dhanjal, J. K., Bhargava, P., Kaul, A., Wang, J., Zhang, H., Kaul, S. C., Wadhwa, R. \& Sundar, D. (2020). Withanone and Withaferin-A are predicted to interact with transmembrane protease serine 2 (TMPRSS') and block entry of SARS-CoV-2 into cells. Journal of Biomolecular Structure and Dynamics, 13. doi.org/10.1080/07391102.2020.1775704

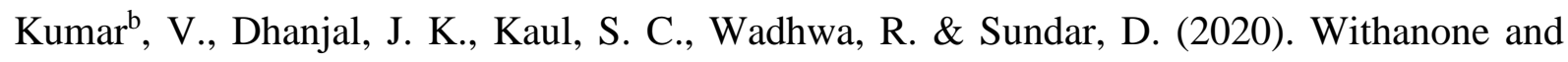
caffeic acid phenethyl ester are predicted to interact with main protease $\left(\mathrm{M}^{\text {pro }}\right)$ of SARS-CoV2 and inhibit its activity. Journal of Biomolecular Structure and Dynamics, 1-14. doi.org/10.1080/07391102.2020.1772108

Labska, K., Plodkova, H., Pumannova, M. \& Sensch, K. H. (2018). Antiviral activity of propolis special extract GH 2002 against Varicella zoster virus in vitro. Pharmazie, 73, 733-736. doi.org/10.1691/ph.2018.8672

Lima, W. G., Brito, J. C. M. \& da Cruz Nizer, W. S. (2021). Bee products as a source of promising therapeutic and chemoprophylaxis strategies against COVID-19 (SARS-CoV-2). Phytotherapy Research. 35, 743-750. doi.org/10.1002/ptr.6872

Marcucci, M. C. (1995). Propolis: chemical composition, biological properties and therapeutic activity, Apidologie, 26, 83-99. doi.org/10.1051/apido:19950202

Maruta H. \& He H. (2020). PAK1-BLOCKERS: Potential Therapeutics against COVID-19. Medicine in Drug Discovery, 6, 100039. doi.org/10.1016/j.medidd.2020.100039

Ohkuara, N., Maruyama, K. \& Kihara-Negishi, F. (2020). Possible antithrombotic properties of propolis. Journal of Apitherapy, 7(1), 1-9. doi.org/10.5455/ja.20190807071847

Refaat, H., Mady, F. M., Sarhan, H. A., Rateb, H. S. \& Alaaeldin, E. (2021). Optimization and evaluation of propolis liposomes as a promising therapeutic approach for COVID-19. International Journal of Pharmaceutics, 592, 120028. doi.org/10.1016/j.ijpharm.2020.120028 Ripari, N., Sartori, A. A., da Silva Honorio, M., Conte, F. L., Tasca, K. I., Santiago, K. B. \& Sforcin, J. M. (2021). Propolis antiviral and immunomodulatory activity: a review and perspectives for COVID-19 treatment. Journal of Pharmacy and Pharmacology, 73(3), 281299. doi.org/10.1093/jpp/rgaa067

Sahlan, M., Irdiani, R., Flamandita, D., Aditama, R., Alfarraj, S., Ansari, M. J., Khayrani, A. C., Pratami, D. K. \& Lischer, K. (2021). Molecular interaction analysis of Sulawesi propolis compounds with SARS-CoV-2 main protease as preliminary study for COVI-19 drug 
discovery. Journal of King Saud University, $33(1), \quad 101234$. doi.org/10.1016/j.jksus.2020.101234

Santos, L. M., Fonseca, M. S., Sokolonski, A. R., Deegan, K. R., Araujo, R. P. C., UmszaGuez, M. A., Barbosa, J. D. V., Portela, R. D. \& Machado, B. A. S. (2019). Propolis: types, composition, biological activities, and veterinary product patent prospecting. Journal of the Science of Food and Agriculture, 100, 1369-1382. doi.org/10.1002/jsfa.10024

Shi, Z. H., Li, N. G., Tang, Y. P., Wei, L., Lian, Y., Yang, J. P., Hao, T. \& Duan, J. A. (2012). Metabolism-based synthesis, biologic evaluation and SARs analysis of O-methylated analogs of quercetin as thrombin inhibitors, European Journal of Medicinal Chemistry, 54, 210-212. doi.org/10.1016/j.ejmech.2012.04.044

Singh, S., Sk, M. F., Sonawane, A., Kar P. \& Sadhukhan, S. (2020). Plant-derived natural polyphenols as potential antiviral drugs against SARS-CoV-2 via RNA-dependent RNA polymerase (RdRp) inhibition: an in-silico analysis. Journal of Biomolecular Structure and Dynamics, 28, 1-16. doi.org/10.1080/07391102.2020.1796810

Singhal, T. (2020). A review of coronavirus disease-2019 (COVID-19). Indian Journal of Pediatrics, 87(4), 281-286. doi.org/10.1007/s12098-020-03263-6

Shubharani, R., Mahesh, M. \& Murthy, V. N. Y. (2019). Biosynthesis and Characterization, Antioxidant and Antimicrobial Activities of Selenium Nanoparticles from Ethanol Extract of Bee Propolis. Journal of Nanomedicine and Nanotechnology, 10, 1. doi.org/10.4172/21577439.1000522

Soroy, L., Bagus, S., Yongkie, I. P., \& Djoko, W. (2014). The effect of a unique propolis compound (Propoelix ${ }^{\mathrm{TM}}$ ) on clinical outcomes in patients with dengue hemorrhagic fever. Infection and Drug Resistance, 7, 323-329. doi.org/10.2147/IDR.S71505

Te Velthuis, A. J. W., van den Worm, S. H. E., Sims, A. C., Baric, R. S., Baric, Snijder E. J. \& van Hemert, M. J. (2010). Zn2+ inhibits Coronavirus and Arterivirus RNA Polymerase activity in vitro and zinc ionophores block the replication of these viruses in cell culture. PLoS Pathogens, 6(11), e1001176. doi.org/10.1371/journal.ppat.1001176

Tosic, S., Stojanovic, G., Mitic, S., Pavlovic, A. \& Alagic, S. (2017). Mineral Composition of Selected Serbian Propolis samples. Journal of Apicultural Science, 61(1), 5-15. doi.org/10.1515/jas-2017-0001 
United States Food and Drug Administration. 2020. FDA cautions against use of hydroxychloroquine or chloroquine for COVID-19 outside of the hospital setting or a clinical trial due to risk of heart rhythm problems. 2020. Retrieved April 28, 2021 from https://www.fda.gov/safety/medical product-safety-information/hydroxychloroquine-orchloroquine-covid-19-drug-safety-communication-fda-cautions-against-use. In text reference: (United States Food and Drug Administration, 2020)

Vijayakumar, B. G., Ramesh, D., Joji, A., Jayachandra Prakasan, J. \& Kannan, T. (2020). In silico pharmacokinetic and molecular docking studies of natural flavonoids and synthetic indole chalcones against essential proteins of SARS-CoV-2. European Journal of Pharmacology, 886, 173448. doi.org/10.1016/j.ejphar.2020.173448

Vipul, K., Dhanjal, J.K., Kaul, S.C., Wadhwa, R. \& Sundar, D. (2020). Withanone and caffeic acid phenethyl ester are predicted to interact with main protease $\left(\mathrm{M}^{\mathrm{pro}}\right)$ of SARS-CoV-2 and inhibit its activity. Journal of Biomelecular Structure and Dynamics, 1, 1-13. doi.org/10.1080/07391102.2020.1772108

Volz, E, Hill, V., McCrone, J.T., Price, A., Jorgensen, D., Toole, A. O. Southgate, J., Johnson, R., Jackson, B., Nascimento, F. F., Rey, S. M., Nicholls, S. M., Colquhoun, R. M., da Silva Filipe, A., Shepherd, J., Pascall, D. J., Shah, R., Jesudason, N., Li, K., Jarrett, R.,...Connor, T. R. (2021). Evaluating the Effects of SARS-CoV-2 Spike Mutation D614G on Transmissibility and Pathogenicity. Cell, 184(1), 64-75.e11. doi.org/10.1016/j.cell.2020.11.020

WHO. (2021a). Retrieved April 27, 2021 from https://www.who.int/emergencies/diseases/novelcoronavirus2019?gclid=Cj0KCQjwyZmEBh CpARIsALIzmnKDVG9NN9IY9VnZ46UYJw4VXCrjihnt7kqPUQUW6nSprhThpL5nZDca AvoZEALw_wcB. In text reference: (WHO, 2021a).

WHO. (2021b) Retrieved April 27, 2021 from https://www.who.int/healthtopics/coronavirus\#tab=tab_3. In text reference: (WHO, 2021b).

Yildirim, A., Duran, G. G., Duran, N., Jenedi, K., Bolgul, B. S., Miraloglu, M. \& Muz, M. (2016). Antiviral activity of Hatay Propolis against replication of Herpes Simplex Virus Type 1 and Type 2. Medical Science Monitor, 22, 422-430. doi.org/10.12659/MSM.897282

Zhang, L., Jackson, C. B., Mou, H., Ojha, A., Peng, H., Quinlan, B. D., Rangarajan, E. S., Pan, A., Vanderheiden, A., Suthar, M.S., Li, W., Izard, T., Rader, C., Farzan, M. \& Choe, H. (2020). 
SARS-CoV-2 spike-protein D614G mutation increases virion spike density and infectivity. Nature Communication, 11, 6013. doi.org/10.1038/s41467-020-19808-4

Zitek, T. (2020). The Appropriate Use of Testing for COVID-19. The Western Journal of Emergency Medicine, 21(3), 470-472. doi.org/10.5811/westjem.2020.4.47370

Zulhendri, F., Felitti, R., Fearnley, J. \& Ravalia, M. (2021). The use of propolis in dentistry, oral health, and medicine: A review. Journal of Oral Biosciences, 63(1), 23-34. doi.org/10.1016/j.job.2021.01.001 